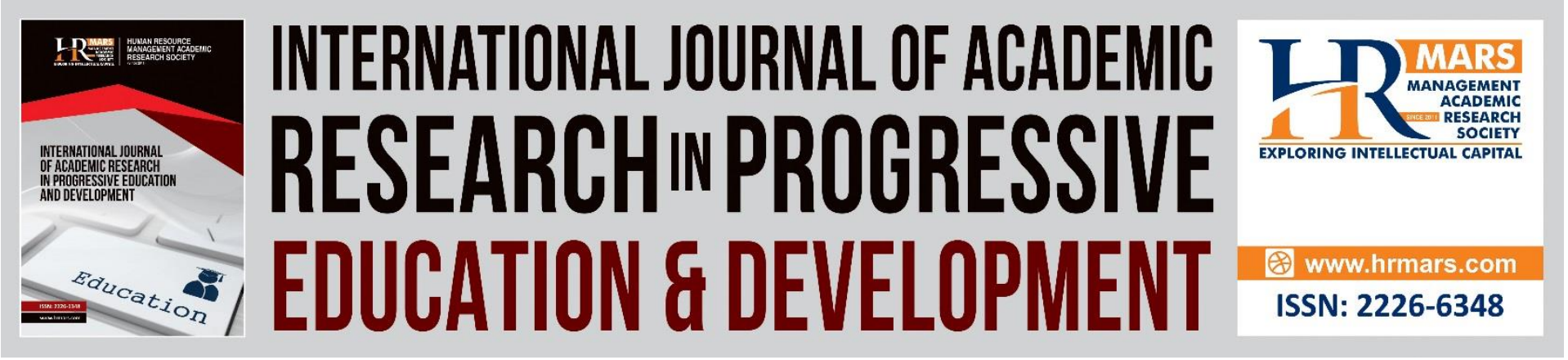

\title{
A Study of Sports Performance Monitoring on Individual Sports and Team Sports Physical Fitness Performance Using Multivariate Approach
}

Noor Aishah Kamarudin, Mohamad Razali Abdullah, Rabiu Muazu Musa, Vijayamurugan Eswaramoorthi, Ahmad Bisyri Husin Musawi Maliki, Aina Munirah Ab Rasid, Ahmad Nadzmi

To Link this Article: http://dx.doi.org/10.6007/IJARPED/v11-i1/12065

DOI:10.6007/IJARPED/v11-i1/12065

Received: 06 November 2021, Revised: 30 November 2021, Accepted: 17 December 2021

Published Online: 14 January 2022

In-Text Citation: (Kamarudin et al., 2022)

To Cite this Article: Kamarudin, N. A., Abdullah, M. R., Musa, R. M., Eswaramoorthi, V., Maliki, A. B. H. M., Rasid, A. M. A., \& Nadzmi, A. (2022). A Study of Sports Performance Monitoring on Individual Sports and Team Sports Physical Fitness Performance Using Multivariate Approach. International Journal of Academic Research in Progressive Education and Development, 11(1), 331-341.

Copyright: (C) 2022 The Author(s)

Published by Human Resource Management Academic Research Society (www.hrmars.com)

This article is published under the Creative Commons Attribution (CC BY 4.0) license. Anyone may reproduce, distribute, translate and create derivative works of this article (for both commercial and non-commercial purposes), subject to full attribution to the original publication and authors. The full terms of this license may be seen at: http://creativecommons.org/licences/by/4.0/legalcode

Vol. 11(1) 2022, Pg. 331 - 341 


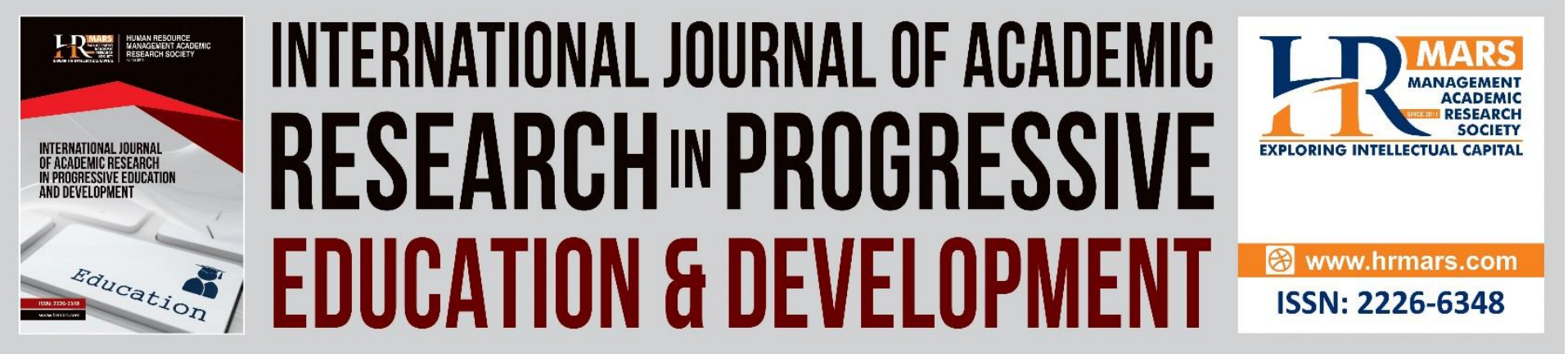

\title{
A Study of Sports Performance Monitoring on Individual Sports and Team Sports Physical Fitness Performance Using Multivariate Approach
}

\author{
Noor Aishah Kamarudin', Mohamad Razali Abdullah², Rabiu \\ Muazu Musa ${ }^{3}$, Vijayamurugan Eswaramoorthi ${ }^{4}$, Ahmad Bisyri \\ Husin Musawi Maliki ${ }^{5}$, Aina Munirah Ab Rasid ${ }^{6}$, Ahmad \\ Nadzmi ${ }^{7}$ \\ ${ }^{1,4}$ Faculty of Health Sciences, Universiti Sultan Zainal Abidin. 21300 Kuala Nerus,
} Terengganu, Malaysia, ${ }^{2}$ East Coast Environmental Research Institute' Universiti Sultan Zainal Abidin. 21300 Kuala Nerus, Terengganu, Malaysia, ${ }^{3}$ Centre for Fundamental and Liberal Education, Universiti Malaysia Terengganu. 21030 Kuala Nerus, Terengganu, Malaysia

${ }^{5,7}$ Academy of Defence Fitness, National Defence University of Malaysia, Kem Sungai Besi, 57000 Kuala Lumpur, Malaysia, ${ }^{6}$ Centre for Fundamental and Continuing Education, Universiti Malaysia Terengganu. 21030 Kuala Nerus, Terengganu, Malaysia Co-author: rabiumuazu86@gmail.com

\begin{abstract}
Performance monitoring has been used for many years and various fields including sports regardless of whether it is individual sports or team sports in order to evaluate and monitor the athlete's performance. The purpose of this study is to identify the differences of physical fitness performance between individual sports and team sports using multivariate approach. Malaysian Game's junior athlete in age range of 13 to 21 years old were participated in this study. Tests used in this study were divided by two based on fitness component, Health Related Fitness Component and Skill Related Component. Tests that involved were sit and reach, sit up, push up, handgrip, predicted $\mathrm{VO}_{2} \mathrm{max}$, medicine ball throw, 20 meter sprint test, vertical jump, stork stand test, standing broad jump, and T test. Multivariate Analysis of Variance method was used to analyse the test's result. The analysis resulting there are some tests shows the significant differences between both individual sport and team sports. From the analysis, can be simplified that there are some physical fitness components that each type of sports excels and required in specification phase in performance monitoring. Keyword: Performance Monitoring, Physical Fitness Performance, Individual Sports, Team Sports
\end{abstract}

\section{Introduction}

Since the last several decades, performance monitoring has been frequently utilized by all sport practitioners throughout the world. (Vaeyens et al., 2012). Performance 
monitoring is also applied in a variety of fields, including business, art, music, and many more. (Abbot et al., 2005). Performance monitoring has been utilised in the sport area to identify existing players with the ability to excel in sports, as well as to admit individuals into representative teams and development programmes. It also entails an effort to predict an individual's future performance capacity (Abbott \& Collins, 2010; Vaeyens et al., 2012). In sport performance monitoring, athlete selection has been divided into four stages, these being detection, identification, selection and development (Reilly \& Williams, 2003). Detection involves identifying suitable players that are not currently playing the sport. From the detection, athletes can monitor whether they can participate in suitable type of sports neither individual sports or team sports.

Individual sport and team sport both has their own characteristic. Team sports need a group of individuals that will be organized into opposing teams which compete to win. So, there will be many tactical and strategies available that require aggressiveness, sudden pacechange, counter attacks and defensives. So, in order to execute the strategies, optimum fitness performance needed to execute the tactical and to cover up the strength and weakness available on each athlete. Same also with individual sport, that only performing the play alone and all the performance are the athletes alone to bear. In order to avoid performance flop and cover weakness component to be spotted by the opponent, at least an optimum physical fitness need to be ready in match

Physical fitness is well acknowledged to have a significant influence on sport analysis in TID. In physical fitness performance, there are two main components in physical fitness component that is Health Related Fitness Component (HRFC) and Skill Related Fitness Component (SRFC). HRFC is a basis from which to measure our general wellbeing. It is the aim of exercise to improve our capabilities in each of these areas and SRFC is an underlying skill which are brought to bear when participating in a sport. There is two disciplines of sport performance analysis, Biomechanics and Notational (Hughes \& Bartlett, 2015). Biomechanics study is typically focused on the movement skill of particular athletes. It utilizes kinematic variables or parameters as performance indicators. On the other hand, notational analysis focuses on gross motions or movement patterns in team sports. It is mostly concerned with strategy and tactics. Match, tactical, and technical performance indicators are all used. Certain physical fitness characteristics, such as age, body flexibility, BMI, core body strength, upper body strength, and endurance, may be factors that influence sport performance results. All of this discipline to be implemented by all sport organisations when organizing sport performance monitoring programmes.

While many sport organisations use performance monitoring programmes, there does not appear to be a clear set of criteria that consistently predict future performance, according to the authors, who also state that performance monitoring programmes are an important aspect of the elite-level athlete selection process. While performance monitoring programmes are used by many sports organisations, there does not appear to be a clear set of criteria that reliably predict future performance (Johnston et al., 2017). Right now in the best of our knowledge, there is no universally acknowledged theoretical framework to guide contemporary practise, and there is no consensus on how talent should be defined or discovered (Vaeyens et al., 2012). This problem required more discoveries of optimum physical fitness in sport diversities. To identify those optimum physical fitness both individual and team sports, a multivariate analysis must be done. Actually, there is a opinion conflict on Baker et al opinion of multivariate analysis in sport performance monitoring between Hart, (2018) and Silva et al., (2019). Baker et al., (2018) stating that multivariate in performance 
monitoring are not promising and problematic because lack of time frame and multivariate is a short-term analysis but Hart (2018) study proved that multivariate models is suitable and could significantly predict overall health-related fitness in both males and females. Also, Silva et al (2019) proved that multivariate analysis enabled them to observe the differences between skill levels among athlete at that time. The aim of this study is to identify the differences of physical fitness performance between individual sports and team sports using multivariate approach.

\section{Methodology Participants}

The study's subjects are Malaysia junior male athletes aged 13 to 21 who are participate in the Malaysian games. There have been eight different forms of sports, with five different types of individual sports and three different types of team sports. Throughout the research period, the athlete's overall physical fitness test was taken and assessed. All of the athletes signed consent papers, which have been collected in writing. The Malaysia Sports Institute Council (MSN) Ethics Board examined and approved all of the study's protocols, protocol, and equipment.

\section{Health Related Fitness Component (HRFC)}

Standard physical fitness evaluations were used in conjunction with routine physical fitness indicators such as sit and reach, 1 minute sit up, push up, hand-grip test, predicted VO $2 \mathrm{Max}$, and medicine ball throw test. Before the testing periods, the athletes conducted a warm-up that included a 5 to 10 minute jog and a series of stretch-es.

\section{Sit and Reach}

Athletes must sit on the ground with straight legs, knees on the ground, and feet facing the flat surface of the sit and reach box when conducting sit and reach (Ryan et al., 2014). With little pressure, the facilitator keeps the participant's sides of the knees straight against the floor. With their hands on top of each other, the athletes gently pushed forward their fingertips while moving the measuring slide as far as possible over the measurement line. While recording the distance, the conductor must maintain the reach for at least two seconds. The conductor must ensure that the athletes' fingers and legs are in a stable straight posture with no jerky movements. The findings of the test must be recorded in $0.5 \mathrm{~cm}$ increments.

\section{Sit up}

Sit up test used to measure core muscle strength (CMS). Sit-up test with knees bent on the ground at 90 degrees and feet flat and push-up testing with extended legs were performed (Abdullah et al., 2016). The number of completed sit-ups and push-ups in 1-minute was recorded.

\section{Push up}

In this test, the upper muscular strength (UMS) was examined. The athletes sat on the floor in a prone posture with their hands just below their shoulders, stretched legs, and tucked toes in order to make contact with the floor (push up position). The athletes then extend their arms to their full length before lowering their bodies to the floor and lowering their chests. At this stage, the line from head to toe should be straight. (Abdullah et al., 2017). 
DEVELOPMENT

Vol. 11, No. 1, 2022, E-ISSN: 2226-6348 @ 2022 HRMARS

All of these actions were executed only by the arms and shoulders. The score was determined by the number of push-ups while maintaining correct form until the athletes are exhausted.

\section{Handgrip Test}

Hand grip (HG) was used to measure the maximum isometric strength of the hand and forearm muscles of the athletes (Taha et al., 2018). To conduct this test, a hand grip dynamometer was utilised, and archers were instructed to hold the dynamometer in the hand to be studied, with the arm at right angles and the elbow at the side of the body. The dynamometer's knob is changed based on the athlete's height. The first metacarpal (heel of the palm) served as the basis of the hand grasp, with the handle resting in the midst of four fingers. When the participants were ready, they were allowed to squeeze the dynamometer with maximum isometric effort for roughly 5 seconds. Other types of bodily movement were not authorised. The researchers urged the athletes to put up their best effort. Both hands were simultaneously used.

\section{Predicted VO2max}

Predicted VO $2 \mathrm{Max}$ is a multistage 20-meter shuttle run test that was used to determine the participant's predicted cardiovascular ability (Suhaimi et al., 2021). The athlete ran as long as they could till they couldn't keep up with the speed of the tape. All test results were expressed as an estimated VO2max, which was derived by looking at the final level and shuttle number when the person voluntarily surrendered from the test. Although the athletes' motivation and drills may impact their scores, it is still a viable test for measuring projected maximal oxygen intake and may be administered to a large number of athletes at a low cost and time.

\section{Medicine Ball Throw}

The overhead throw for distance is a test of upper body strength that involves throwing the ball forwards from over the head. Medicine ball throw tests are used to assess upper muscle power. The standing medicine ball consisted of beginning with the width of the feet, the heels on the measuring line zero and keeping the medicine ball straight out at the foot (Stockbrugger \& Haennel, 2001). Athletes were permitted to practise trials at least 5 to 6 times in order to get a consistent score and become comfortable with the needed technique, which included optimising the angle of release and maximum power output. After completing the trial, competitors were permitted to take the exam for the real scoring session. Three timed trials were conducted in which they attempted to toss a medicine ball as far as possible. The distance of each throw was measured (meters).

\section{Skill Related Fitness Component (SRFC)}

The 20-meter sprint, vertical jump test, standing stork test, standing broad jump test, and $T$ test are all skill-related fitness component tests.

\section{0-meter Sprint Test}

20-meter sprint (20MS) was carried out by following procedure in EUROFIT test battery (Nadzmi et al., 2021). Before beginning the test, athletes were advised to stand in a ready-to-run stance, with one dominant leg placed at the starting point to function as a momentum starter for the participant to sprint. The facilitator will blow the whistle, and the athlete will begin the run. The time begins to be recorded when the athletes begins to run 
DEVELOPMENT

Vol. 11, No. 1, 2022, E-ISSN: 2226-6348 @ 2022 HRMARS

from the starting line and ends when the athletes reaches the finish line. Intermittently, each participant receives two trials. Readings will be taken to the nearest two decimal points $(0.01)$ seconds.

\section{Vertical Jump}

Vertical jump used to measure lower body strength. The height of the color-coded plastic vanes was modified so that it was in line with the athletes' standing height. The athlete flexed their ankles, knees, and hips, swung their arms upward, and tapped the highest possible vane with their dominant hand's fingers (Bisyri et al., 2018.). For statistical analysis, the best of the three trials was chosen.

\section{Stork Stand Test}

Stork test used to measure body balance. The standing stork (SS) test was timed with a stopwatch. The athletes removed their shoes, placed their hands on their hips, rose their heels to balance on the ball of their foot, and placed their non-supporting foot underneath the supporting leg. (Schorderet et al., 2021). The test is canceled if the athletes are unable to maintain the exact leg position.

\section{Standing Broad Jump}

Leg explosive power was measured using the Standing Broad Jump test. Standing broad jump (SBJ) participants must stand behind a line that has been put in the area. After a two-foot take-off leap, the athletes will land with their arms swinging back and their knees bent rhythmically at around 90 degrees forward. The athletes must land on both feet and jump as far as they can without falling backwards. The test will be rejected if the athletes does not follow the protocol. (Nadzmi et al., 2021). At that time only three trials were allowed, with the highest score getting kept.

\section{T test}

The 'T-test agility test' was used to determine agility. The protocol was followed exactly as it had been specified. The pointers are placed 10-5-5 metres apart on a line drawn on the ground in the shape of a ' $T$ '. The athletes run from the $10 \mathrm{~m}$ marker near the line, through the $5 \mathrm{~m}$ markers, turn on the line, and sprint back over the $5 \mathrm{~m}$ markers. The time is recorded using an infrared speed trap (Brower Timing system) from when the athlete first runs through the $5 \mathrm{~m}$ back to $10 \mathrm{~m}$ markers until they halt. Each athlete attempted two times at their maximum, with the fastest time being recorded for analysis. The participant was advised not to cross the line too far because it would lengthen their time.

\section{Statistical Analysis}

Multivariate Analysis of Variance (MANOVA) method was used in this study by using Statistical Package for the Social Sciences (SPSS). MANOVA is a member of the General Linear Model-a family of statistical procedures that are often used to quantify the strength between variables (Zientek \& Thompson, 2009). MANOVA, specifically, is an analysis of variance (ANOVA) that has two or more dependent variables (Fish, 1988). In this study, MANOVA will be used to identify the pros and cons of physical performance for each type of sport, individual sport athlete and team sport athlete by using Pairwise Comparison method. This method will show the mean difference between the mean of the analysis (I-J). From the 
analysis, the test that have significant difference in $p$ value will be chosen to observe the mean difference between the tests.

\section{Result and Findings}

Table 1 shows the result of MANOVA, showing that there are some significant differences in physical performance between individual sport and team sport. In HRFC test, tests that have significant value are Push Up, Predicted VO2max, and Medicine Ball Throw with significant value for each test Push Up ( $\operatorname{Pr}>f=0.000)$, Predicted VO2max $(\operatorname{Pr}>f=0.013)$, and Medicine Ball Throw $(\operatorname{Pr}>f=0.000)$. As for SRFC test, all the test showing significant value (20 meter sprint test, Vertical Jump, and Standing Broad Jump ( $\operatorname{Pr}>f=0.000), T$ Test $(\operatorname{Pr}>f=$ 0.049) except Stork Stand did not showing significant value.

For significant HRFC tests, showing that in Push Up test, team sport was better than individual sport with mean difference (-20.805). Predicted VO2max test showing individual sport was better than team sport with mean difference (-3.218). For last significant test Medicine Ball Throw, showing also individual sport was better than team sport with mean difference (-.976).

As for significant SRFC tests, 20 meter sprint test resulting individual sport was better than team sport with mean difference (.236). Vertical Jump showing team sport was better than individual sport with mean difference (-12.470). As for standing broad jump test, individual sport showing domination on this test among team sport with mean difference (20.142). Individual sport also showing supremacy in the T Test by showing better performance than team sport with mean difference (.311). 
INTERNATIONAL JOURNAL OF ACADEMIC RESEARCH IN PROGRESSIVE EDUCATION AND

DEVELOPMENT

Vol. 11 , No. 1, 2022, E-ISSN: 2226-6348 @ 2022 HRMARS

Table 1: MANOVA analysis with Pairwise Comparison result of study

\begin{tabular}{|c|c|c|c|c|c|c|c|}
\hline \multicolumn{2}{|c|}{ Variable } & \multirow{2}{*}{$\begin{array}{l}\text { Group (I) } \\
\text { INDIVIDUAL }\end{array}$} & \multirow{2}{*}{$\begin{array}{l}\text { Group (J) } \\
\text { TEAM }\end{array}$} & \multirow{2}{*}{$\begin{array}{l}\text { Mean } \\
39.17\end{array}$} & \multirow{2}{*}{$\begin{array}{l}\text { Mean } \\
\text { Difference (I- } \\
\text { J) } \mathbf{M} \\
-0.113\end{array}$} & \multicolumn{2}{|c|}{$\begin{array}{l}\text { Sig.Difference } \\
p\end{array}$} \\
\hline \multirow{12}{*}{ 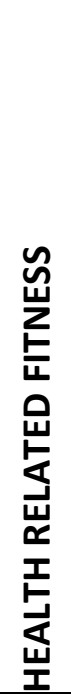 } & SIT \& REACH & & & & & 0.915 & \\
\hline & & TEAM & INDIVIDUAL & 39.06 & 0.113 & 0.915 & \\
\hline & 1 MINUTE SIT & INDIVIDUAL & TEAM & 41.76 & -1.984 & 0.230 & \\
\hline & UP & TEAM & INDIVIDUAL & 39.78 & 1.984 & 0.230 & \\
\hline & PUSH UP & INDIVIDUAL & TEAM & 38.32 & $20.805^{*}$ & 0.000 & $*$ \\
\hline & & TEAM & INDIVIDUAL & 59.13 & $-20.805^{*}$ & 0.000 & $*$ \\
\hline & HANDGRIP & INDIVIDUAL & TEAM & 45.06 & -2.555 & 0.055 & \\
\hline & & TEAM & INDIVIDUAL & 42.51 & 2.555 & 0.055 & \\
\hline & PREDICTED VO & INDIVIDUAL & TEAM & 45.24 & $-3.218^{*}$ & 0.013 & $*$ \\
\hline & $2 \mathrm{MAX}$ & TEAM & INDIVIDUAL & 42.02 & $3.218^{*}$ & 0.013 & $*$ \\
\hline & MEDICINE & INDIVIDUAL & TEAM & 7.19 & $-.976^{*}$ & 0.000 & $*$ \\
\hline & BALL THROW & TEAM & INDIVIDUAL & 6.22 & $.976^{*}$ & 0.000 & $*$ \\
\hline \multirow{10}{*}{ 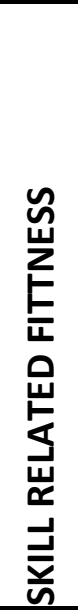 } & 20 METER & INDIVIDUAL & TEAM & 3.17 & $.236^{*}$ & 0.000 & $*$ \\
\hline & SPRINT TEST & TEAM & INDIVIDUAL & 3.41 & $-.236^{*}$ & 0.000 & $*$ \\
\hline & VERTICAL & INDIVIDUAL & TEAM & 33.01 & $12.470^{*}$ & 0.000 & $*$ \\
\hline & JUMP & TEAM & INDIVIDUAL & 45.47 & $-12.470^{*}$ & 0.000 & $*$ \\
\hline & STANDING & INDIVIDUAL & TEAM & 233.7 & $-20.142^{*}$ & 0.000 & $*$ \\
\hline & BROAD JUMP & TEAM & INDIVIDUAL & 213.5 & $20.142^{*}$ & 0.000 & $*$ \\
\hline & STORK STAND & INDIVIDUAL & TEAM & 29.47 & -1.080 & 0.819 & \\
\hline & TEST & TEAM & INDIVIDUAL & 28.39 & 1.080 & 0.819 & \\
\hline & T TEST & INDIVIDUAL & TEAM & 11.13 & $.311^{*}$ & 0.049 & $*$ \\
\hline & & TEAM & INDIVIDUAL & 11.45 & $-.311^{*}$ & 0.049 & $*$ \\
\hline
\end{tabular}

\section{Discussion}

The purpose of this study is to identify the differences of physical fitness performance between individual sports and team sports using multivariate approach. From the findings above, can be see that individual sport have some good component and the analysis showing that individual sport is good in cardiovascular, upper body strength, speed, leg explosive power, and agility while team sport is only good at upper muscular strength and lower body strength.

For HRFC tests, can be seen individual sport athlete dominating in cardiovascular and upper body strength. This is similar to the past research from Pickett et al (2018) stating that individual sport, upper body strength and cardiovascular have a substantial relationship with physical fitness performances. Sporer \& Wenger (2003) stating the relationship of the upper body strength and cardiovascular capabilities showing that as the higher the upper body strength, the longer the athletes can perform during in match. This is reasonable for performance monitoring in individual sport as the individual sports usually contribute to a long time period that require the athlete's performance consistency such as long-range athletics sports or long range aquatic sport or short time explosive burst performance such as 
combat sport, tenpin bowling and short range athletic sport. In SRFC, showing individual sport is good at speed, agility, and leg explosive power. This findings supported by past study stating for athletes in individual sports have acceptable levels of explosive strength, sprinting, acceleration, and deceleration (Sole et al., 2021).

Founded also team sport athlete were good in upper muscle strength and lower muscle strength. This is seemed legitimate for performance monitoring application due to team sport playstyle require vigorous performance on specific component. For example, in rugby sport, founded that upper and lower muscular strength are essential factors in determining a team sport athlete's success (Maud, 1983). Another example in football sports, stating that football player have a great muscular strength between and athletes of college students but athletes were better in speed, explosive strength and agility than football players (Islam, 2017). Also in another study, lower body strength, along with anthropometry, was one of the best indicators of status and hence an essential test for evaluating prospective talent in team sport athletes. (Woods et al., 2015). Simplified here the physical fitness component requirement were different in each sport but from the past literature stated, founded both upper and lower body strength were required in for team sport selection and both components are suitable to be implemented in performance monitoring.

\section{Conclusion}

From the significant differences resulted from the analysis above, can be seen there are some physical fitness tests shown significant differences for each type of sports in the analysis result. From the significant differences between the test, it can be simplified that individual sports resulting better performance in both HRFC and SRFC than team sports. From it, can be suggested to the coaches in monitoring athlete performance process to manoeuvre the process concurrently in order to sustain the athlete performance. From this result also showed the variable of performance monitoring become narrower for each type of sport, and from this the coaches can monitor the athlete's performance specifically based on the athlete's type of sport. A narrow performance monitoring can produce more high quality athlete and evade unnecessary expenses because of application of focused variable during performance monitoring instead of general variable applied during the process. Further study recommended by developing a prediction model based on these findings.

\section{References}

Abbot, A., Button, C., Pepping, G.-J., \& Collins, D. (2005). Unnatural selection: Talent identification and development in sport. Nonlinear Dynamics, Psychology and Life Sciences, 9(1). https://www.researchgate.net/publication/8102048

Abbott, A., \& Collins, D. (2010). A Theoretical and Empirical Analysis of a "State of the Art" Talent Identification Model. Taylor \& Francis Online, 13(2), 157-178. https://doi.org/10.1080/1359813022000048798

Abdullah, M. R., Bisyri, A., Maliki, H. M., Musa, R. M., Kosni, N. A., Juahir, H., \& Haque, M. (2016). Multi-Hierarchical Pattern Recognition of Athlete's Relative Performance as A Criterion for Predicting Potential Athletes. Journal of Young Pharmacists, 8(4), 463-470. https://doi.org/10.5530/jyp.2016.4.24

Abdullah, M. R., Nidzam, M. S., Hairi, A., Musa, R. M., Bisyri, A., Maliki, H. M., \& Kosni, N. A. (2017). Prediction of Specific Physical Characteristic and Fitness Related Variables on Cardiovascular Endurance among some Selected Male Uniform Arm Units of Universiti Sultan Zainal Abidin, Malaysia. In Health \& Exercise (Vol. 6, Issue 1). 
Baker, J., Schorer, J., \& Wattie, N. (2018). Compromising Talent: Issues in Identifying and Selecting Talent in Sport. Jörg Schorer \& Nick Wattie, 70(1), 48-63. https://doi.org/10.1080/00336297.2017.1333438

Bisyri, A., Maliki, H. M., Abdullah, M. R., Juahir, H., Abdullah, F., Ain, N., Abdullah, S., Musa, R. M., Musliha Mat-Rasid, S., Adnan, A., Azura Kosni, N., Amalina, W. S., Muhamad, W., Afiqah, N., \& Nasir, M. (2017). A multilateral modelling of Youth Soccer Performance Index (YSPI) Related content The role of anthropometric, growth and maturity index (AGaMI) influencing youth soccer relative performance $A$ multilateral modelling of Youth Soccer Performance Index (YSPI). https://doi.org/10.1088/1757-899X/342/1/012057

Fish, L. J. (2018). Why Multivariate Methods are Usually Vital. 21(3), 130-137. https://doi.org/10.1080/07481756.1988.12022895

Hart, P. D. (2018). Multivariate Analysis of Vertical Jump Predicting Health-related Physical Fitness Performance. American Journal of Sports Science and Medicine, Vol. 6, 2018, Pages 99-105, 6(4), 99-105. https://doi.org/10.12691/AJSSM-6-4-1

Hughes, M., \& Bartlett, R. (2015). What is Performance Analysis? In Essentials of Performance Analysis in Sport (pp. 18-28). Routledge. https://doi.org/10.4324/9781315776743-3

Islam, M. M. (2017). A comparative study on selected physical fitness parameter among college athletes and football players. Journal of Education and Development, $7(13)$.

Johnston, K., Wattie, N., Schorer, J., \& Baker, J. (2017). Talent Identification in Sport: A Systematic Review. Sports Medicine , 48(1), 97-109. https://doi.org/10.1007/S40279017-0803-2

Maud, P. J. (1983). Physiological and anthropometric parameters that describe a rugby union team. British Journal of Sports Medicine, 17(1), 16-23. https://doi.org/10.1136/BJSM.17.1.16

Nadzmi, A., Abdullah, M. R., Maliki, A. B. H. M., Renaldi, F., \& Sukono. (2021). Comparison Between Gross Motor Skills Performance and 7-Years-Old Children with Controlled Effect of Residential Area. Proceedings of the First International Conference on Science, Technology, Engineering and Industrial Revolution (ICSTEIR 2020), 536. https://doi.org/10.2991/ASSEHR.K.210312.007

Pickett, C. W., Nosaka, K., Zois, J., Hopkins, W. G., \& Blazevich, A. J. (2018). Maximal upperbody strength and oxygen uptake are associated with performance in high-level 200-m sprint kayakers. Journal of Strength and Conditioning Research, 32(11), 3186-3192. https://doi.org/10.1519/JSC.0000000000002398

Reilly, T., \& Williams, M. (2003). Introduction to science and soccer. In Science and soccer (pp. 9-14). Routledge. https://doi.org/10.4324/9780203417553-3

Ryan, E. D., Everett, K. L., Smith, D. B., Pollner, C., Thompson, B. J., Sobolewski, E. J., \& Fiddler, R. E. (2014). Acute effects of different volumes of dynamic stretching on vertical jump performance, flexibility and muscular endurance. Clinical Physiology and Functional Imaging, 34(6), 485-492. https://doi.org/10.1111/cpf.12122

Schorderet, C., Hilfiker, R., \& Allet, L. (2021). The role of the dominant leg while assessing balance performance. A systematic review and meta-analysis. Gait \& Posture, 84, 66-78. https://doi.org/10.1016/J.GAITPOST.2020.11.008

Silva, A. F., Ribeiro, J., Vilas-Boas, J. P., Figueiredo, P., Alves, F., Seifert, L., \& Fernandes, R. J. (2019). Integrated Analysis of Young Swimmers' Sprint Performance. Motor Control, 23(3), 354-364. https://doi.org/10.1123/MC.2018-0014

Sole, S., Ramírez-Campillo, R., Andrade, D. C., \& Sanchez-Sanchez, J. (2021). Plyometric jump training effects on the physical fitness of individual-sport athletes: A systematic review 
with meta-analysis. PeerJ, 9. https://doi.org/10.7717/PEERJ.11004/

Sporer, B. C., \& Wenger, H. A. (2003). Effects of Aerobic Exercise on Strength Performance Following Various Periods of Recovery. National Strength \& Conditioning Association J. Strength Cond. Res, 17(4), 638-644.

Stockbrugger, B. A., \& Haennel, R. G. (2001). Validity and Reliability of a Medicine Ball Explosive Power Test. Journal of Strength and Conditioning Research, 15(4), 431-438. https://doi.org/10.1519/1533-4287(2001)015<0431:VAROAM>2.0.CO;2

Suhaimi, M. Z., Musa, R. M., Suhaimi, M. Z., Abdullah, M. R., Husin, A. B., \& Maliki, M. (2021). The Effect of Body Mass Index on Health-Related Parameters in University Students. Research J. Pharm. and Tech, 14(6). https://doi.org/10.52711/0974-360X.2021.00569

Vaeyens, R., Lenoir, M., Williams, A. M., \& Philippaerts, R. M. (2012). Talent Identification and Development Programmes in Sport. Sports Medicine 2008 38:9, 38(9), 703-714. https://doi.org/10.2165/00007256-200838090-00001

Woods, C. T., Raynor, A. J., Bruce, L., McDonald, Z., \& Collier, N. (2015). Predicting playing status in junior Australian Football using physical and anthropometric parameters. Journal of Science and Medicine in Sport, 18(2), 225-229. https://doi.org/10.1016/J.JSAMS.2014.02.006

Zientek, L. R., \& Thompson, B. (2009). Matrix summaries improve research reports: Secondary analyses using published literature. Educational Researcher, 38(5), 343-352. https://doi.org/10.3102/0013189X09339056 